\title{
Simulating the Thermal Response of High Explosives on Time Scales of Days to
} Microseconds

\author{
J.J. Yoh, M.A. McClelland
}

This article was submitted to American Physical Society Topical Conference on Shock Compression of Condensed Matter Portland, OR, July 20-25, 2003

\section{July 16, 2003}

U.S. Department of Energy

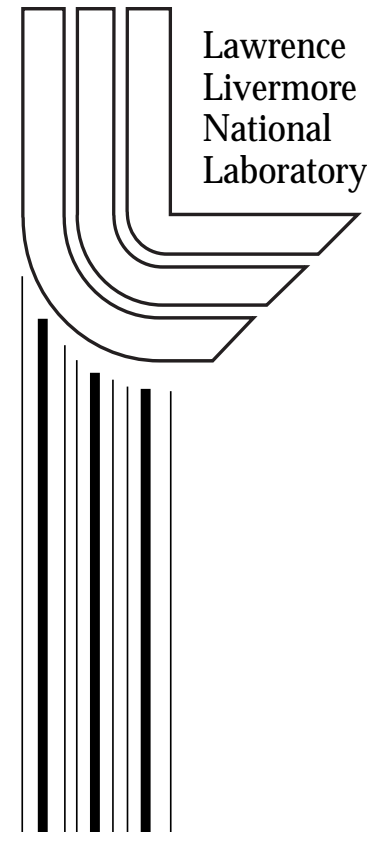




\section{DISCLAIMER}

This document was prepared as an account of work sponsored by an agency of the United States Government. Neither the United States Government nor the University of California nor any of their employees, makes any warranty, express or implied, or assumes any legal liability or responsibility for the accuracy, completeness, or usefulness of any information, apparatus, product, or process disclosed, or represents that its use would not infringe privately owned rights. Reference herein to any specific commercial product, process, or service by trade name, trademark, manufacturer, or otherwise, does not necessarily constitute or imply its endorsement, recommendation, or favoring by the United States Government or the University of California. The views and opinions of authors expressed herein do not necessarily state or reflect those of the United States Government or the University of California, and shall not be used for advertising or product endorsement purposes.

This is a preprint of a paper intended for publication in a journal or proceedings. Since changes may be made before publication, this preprint is made available with the understanding that it will not be cited or reproduced without the permission of the author.

This report has been reproduced directly from the best available copy.

Available electronically at http://www.doc.gov/bridge

Available for a processing fee to U.S. Department of Energy

And its contractors in paper from

U.S. Department of Energy

Office of Scientific and Technical Information

P.O. Box 62

Oak Ridge, TN 37831-0062

Telephone: (865) 576-8401

Facsimile: (865) 576-5728

E-mail: reports@adonis.osti.gov

Available for the sale to the public from

U.S. Department of Commerce

National Technical Information Service

5285 Port Royal Road

Springfield, VA 22161

Telephone: (800) 553-6847

Facsimile: (703) 605-6900

E-mail: orders@ntis.fedworld.gov

Online ordering: http://www.ntis.gov/ordering.htm

OR

Lawrence Livermore National Laboratory

Technical Information Department's Digital Library

http://www.llnl.gov/tid/Library.html 


\title{
SIMULATING THE THERMAL RESPONSE OF HIGH EXPLOSIVES ON TIME SCALES OF DAYS TO MICROSECONDS
}

\author{
Jack J. Yoh* and Matthew A. McClelland* \\ *Energetic Materials Center, Lawrence Livermore National Laboratory, Livermore CA 94551
}

\begin{abstract}
We present an overview of computational techniques for simulating the thermal cookoff of high explosives using a multi-physics hydrodynamics code, ALE3D. Recent improvements to the code have aided our computational capability in modeling the response of energetic materials systems exposed to extreme thermal environments, such as fires. We consider an idealized model process for a confined explosive involving the transition from slow heating to rapid deflagration in which the time scale changes from days to hundreds of microseconds. The heating stage involves thermal expansion and decomposition according to an Arrhenius kinetics model while a pressure-dependent burn model is employed during the explosive phase. We describe and demonstrate the numerical strategies employed to make the transition from slow to fast dynamics.
\end{abstract}

\section{INTRODUCTION}

In the DoD and DOE communities, computational models are being employed to an increasing extent to analyze the performance and safety of weapons systems. Hydrocodes have been used successfully to model the high frequency behavior in shocks and detonations. The multi-time scale behavior encountered in off-normal thermal (cookoff) events such as fires provides additional modeling challenges. For example, the Navy is interested in the behavior of munitions in shipboard fires to help with the design of storage systems and the development of fire fighting procedures. In these fires, time scales for behavior can range from days to microseconds. During the relatively slow heating phase, the response of an energetic materials system is paced by thermal diffusion and chemical decomposition while the mechanical response is essentially a quasi-static process. As the decomposition reactions accelerate, heat is generated faster than it can be removed. Product gases are formed and the resulting pressure rises accelerate the energetic and containment materials. The resulting violence can range from a pressure rupture to a detonation.

The accurate modeling and simulation of cookoff requires an understanding of the mechanical, thermal, and chemical behavior during slow heating and the subsequent explosion $[1,2,3]$. The explosion time and temperature have been successfully predicted using relatively simple thermal analysis codes [4]. However, the prediction of reaction violence requires detailed mechanical models throughout the cookoff event. In particular, dynamic gaps and the generation of thermal damage (porosity and cracks) during slow heating are likely to be important factors. These processes are typically orders of magnitude slower than those associated with the burn phase. Thus, to model a slow cookoff event will require computational tools and models that can handle a wide variety of physical processes and time scales.

In this paper, we describe how the cookoff of high explosives is simulated with the arbitrarily Lagrangian-Eulerian code [5], ALE3D. In particular, we discuss the numerical methodology to transition from slow to fast time scales. We apply our modeling capability to a Scaled Thermal Explosion Experiment (STEX) [6] and compare calculated and measured curves for the wall strain during both the heating and explosive phases of the test. 


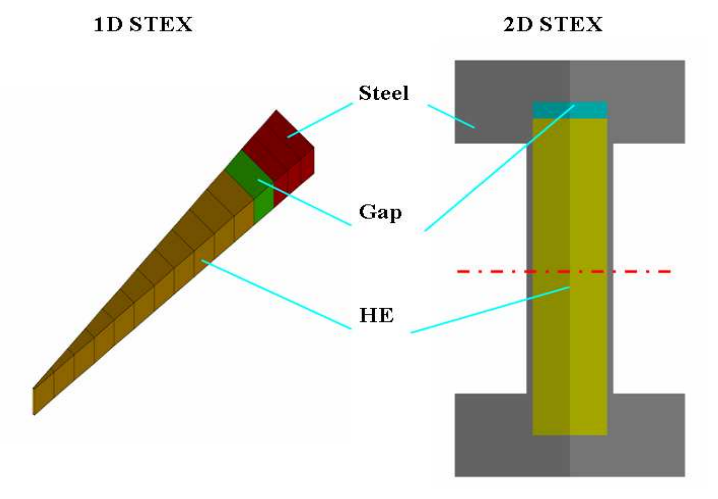

FIGURE 1. Schematics of 1D and 2D STEX domains.

\section{NUMERICAL MODELING OF THE STEX EXPERIMENT}

Fig. 1 shows one and two-dimensional modeling domains for a STEX test involving PBXN-109 (64\% RDX, 20\% Al, 16\% DOA/HTPB). A wedge slice is taken from the center line of the STEX system shown in the right image. This one-dimensional wedge represents an axisymmetric section of the STEX system in which variations occur only in the radial direction. The boundaries at planes of constant $\theta$ are rigid slip surfaces. In the actual experiment [6], the HE, nominally $5.08 \mathrm{~cm}$ diameter is encased in a $0.4 \mathrm{~cm}$ thick steel cylinder. The $5 \%$ ullage by volume is located at the outside radius of the $\mathrm{HE}$ in the $1 \mathrm{D}$ model. The gaps are treated in two different ways in the 2D models. In Model 2Da, a 4\% gap by volume is included at the top end of the cylindrical charge, and a $1 \%$ gap is used at the outside radius of the HE. In Model $2 \mathrm{Db}$, a $5 \%$ gap is included at the top of the cylinder, and there is no gap on the side. The cookoff simulation starts with an increase of the set-point temperature at the steel surface at $5^{\circ} \mathrm{C} / \mathrm{h}$ to $130^{\circ} \mathrm{C}$, followed by a hold for $5 \mathrm{~h}$, and then an increase at a rate of $1^{\circ} \mathrm{C} / \mathrm{h}$ until cookoff. As the PBXN-109 is heated, it thermally expands to fill in the gap. At a temperature above $130^{\circ} \mathrm{C}$, exothermic decomposition begins and eventually ignition occurs near the midplane of the system. On a time scale of microseconds, the propagation of flame through the PBXN109 causes the temperature and pressure to rise, and ultimately causes a break in confinement. In the simulations, three different mesh resolutions (1X, $2 \mathrm{X}$, $4 \mathrm{X})$ are considered. In the base case $(1 \mathrm{X})$, there are
12 elements across the $\mathrm{HE}$ in the radial direction, and in the fine mesh case there are 48 elements in this direction. The air/HE interface is not tracked explicitly, and zones with both air and HE have properties determined by mixing rules.

The equations of mass, momentum, energy, and chemistry are solved on the long time scale of the heating phase and on the short time scale of the thermal runaway phase in a single simulation. The momentum equation is integrated explicitly during both the slow and fast phases. In order to provide computationally feasible step sizes, the method of variable mass scaling [7] is applied during the slow heating phase. The density is increased in the momentum equation to reduce the sound speed and allow larger step sizes consistent with the Courant condition. However, if the time step size and material density are too large, spurious fluctuations, characteristic of a simple harmonic oscillator, appear. Thus, a tradeoff is required between numerical efficiency and accuracy. In practice, the time step size is fixed during the slow heating phase with the density calculated from the Courant condition.

During the transition phase in which the decomposition reactions are accelerating, the time step size is reduced to meet error specifications for the calculation of thermal and composition fields. At the same time, the artificial density is reduced following the Courant condition until the physical value is obtained. When the HE reaches a user-specified temperature, the Arrhenius kinetics expression are replaced by a burn model. A level-set method is used in the modeling of the advancing burn front.

We use the Backward Euler method for the integration of the thermal equations and reaction kinetics during the heating, and transition phases. During the slow heating phase, the time step size is the value selected for the integration of the hydrodynamic equations. A switch is made to an explicit method when the time step size is a user-specified multiple of the Courant time step size calculated with no mass scaling.

\section{ONE-DIMENSIONAL RESULTS}

Calculated results for the wall hoop strain are shown in Fig. 2 for the one-dimensional STEX test. For comparison, the theoretical thermal expansion of an 
TABLE 1. Material properties used in the cookoff simulation. Shown are the density $(\rho)$, coeffi cient of thermal expansion (CTE), shear modulus $(\mu)$, and yield strength $\left(\mathrm{Y}_{0}\right)$.

\begin{tabular}{lrrrr}
\hline & $\begin{array}{r}\rho \\
\left(\mathbf{g} / \mathbf{c m}^{3}\right)\end{array}$ & $\begin{array}{r}\mathbf{C T E} \\
\left({ }^{\mathbf{0}} \mathbf{C}^{-1}\right)\end{array}$ & $\begin{array}{r}\mu \\
(\mathbf{G P a})\end{array}$ & $\begin{array}{r}\mathbf{Y}_{0} \\
(\mathbf{G P a})\end{array}$ \\
\hline PBXN-109 & 1.67 & $1.21 \mathrm{e}-4$ & $4.628 \mathrm{e}-3$ & 0.06 \\
Steel 4340 & 7.83 & $1.20 \mathrm{e}-5$ & 77.0 & 1.03 \\
\hline
\end{tabular}

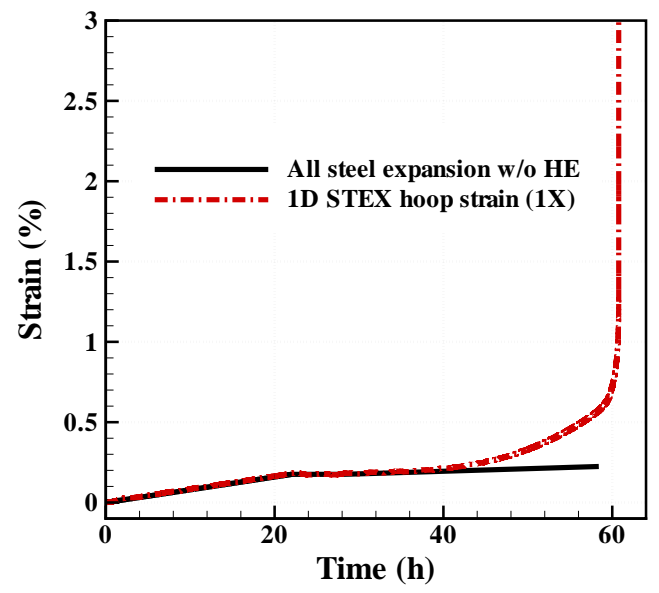

FIGURE 2. Simulated mechanical response of confi ned explosive in a 1D STEX experiment.

empty steel vessel is shown in the same plot. Note that these expansions are constrained to occur in the $r$-direction alone and cannot be calculated from the CTEs alone. As the temperature increases, the HE thermally expands inside the steel vessel at a rate approximately $10 \mathrm{X}$ greater than the steel vessel itself (see Table 1). For $t<38$ hours, the 1D STEX results are in excellent agreement with the theoretical results for the empty vessel. After this point, decomposition gases pressurize the vessel, generating strain values larger than the empty vessel values.

The reaction rate accelerates to the point where where the expansion of the STEX system is taking place on the scale of microseconds. During this acceleration, the three-step kinetics [4] is replaced by the burn model as discussed earlier and the calculation is continued to completion.

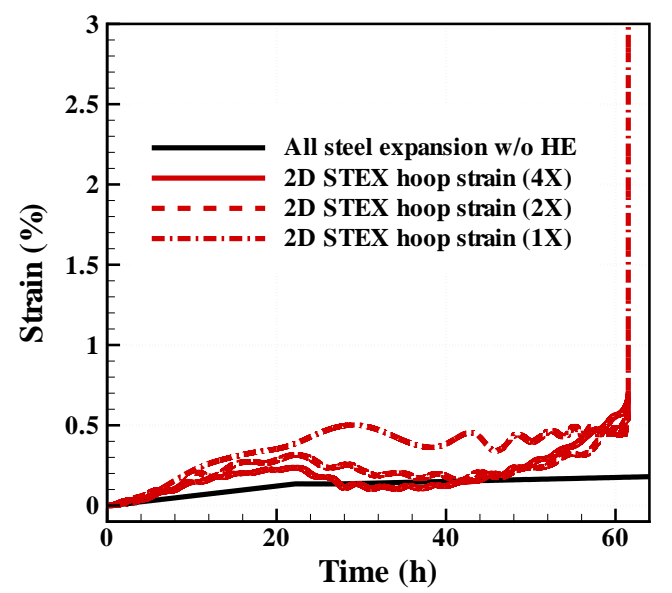

FIGURE 3. Calculated mechanical response of confi ned HE in a 2D STEX experiment.

\section{TWO-DIMENSIONAL RESULTS}

The two dimensional simulations add the influence of variations in the $z$ direction. This system is assumed to be axisymmetric, and a cylindrical wedge was selected for the calculation domain. In Fig. 3, calculated wall hoop strains for the STEX system are presented. As was done for the one-dimensional case, the theoretical expansion of the empty steel vessel is plotted together with the calculated strain results. Shown are the hoop strains for Model 2Da on meshes of three different resolutions. These results are generally higher than the results for pure steel, and show spurious oscillations from the method of mass scaling used in the integration of the momentum equation as described above. The results for the three meshes appear to be approaching a converged solution, but convergence has not yet been achieved. The results for Model 2Da, should match the empty vessel results until the $1 \%$ gap at the side of the $\mathrm{HE}$ cylinder closes at $t=9.4 \mathrm{~h}$ and a strain of $0.056 \%$. It is seen that the Model 2Da curves are higher than the empty vessel curve during this period, indicating that numerical errors of the scale $0.1 \%$ remain. Although these absolute errors are small, the associated changes in HE pressure are large given the large elastic modulus for steel.

A rapid expansion of the vessel wall follows the slowing heating and ignition phases. In Fig. 4, wall 


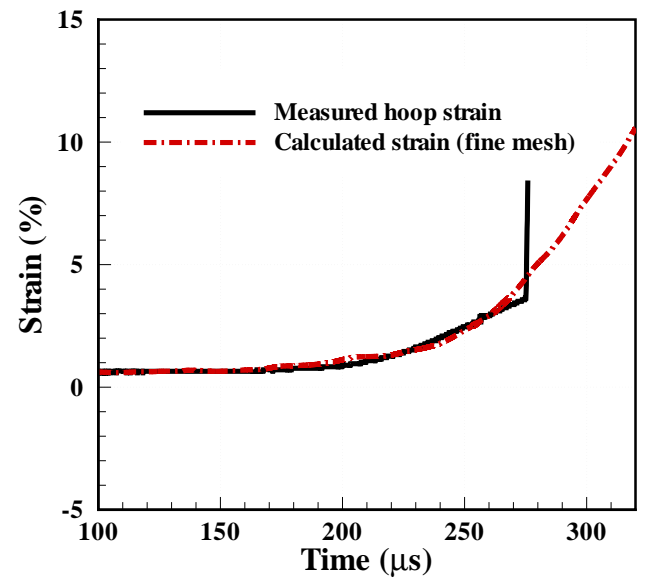

FIGURE 4. Comparison of measured and calculated hoop strains during a thermal runaway.

strain results for Model 2Db (no side gap) are compared with the measured hoop strain results for the STEX test. The model results compare favorably with the measured results until $t=275 \mu \mathrm{s}$. At this time, the measured strain rate changes dramatically. It is likely, that the gauge failed at this point.

Although the model provides a good representation of the measurements, mesh refinement results need to be completed to establish the numerical accuracy of the calculations. In addition, the gap at the side of the HE needs to be added to provide a more complete model.

\section{CONCLUSIONS}

Progress has been made towards the modeling of violence in slow cookoff using the ALE3D code. Numerical procedures have been developed to model the thermal, mechanical, and chemical behavior during the slow heating, transition, and explosive phases in a single simulation. In this paper attention is focused on the accuracy of mechanical results for the simulation of a STEX test with PBXN-109. For the heating phase, an explicit hydro scheme with mass scaling provides numerically accurate results for wall strains in one-dimension and approximate results in two dimensions. For the rapid expansion, the model provides a good representation of mea- sured wall strains. However, a better treatment of gaps is needed during the heating phase to confirm the numerical accuracy of these model results. An implicit hydro scheme with slide surfaces is being developed to provide improved accuracy for cookoff systems with gaps.

\section{ACKNOWLEDGMENTS}

Support for this work was provided by the DoD Office of Munitions through DoD/DOE Memorandum of Understanding. The work was performed under the auspices of the U.S. Department of Energy by the University of California, Lawrence Livermore National Laboratory under Contract No. W-7405-Eng48.

\section{REFERENCES}

1. McClelland, M. A., Maienschein, J. L., Nichols, A. L., Wardell, J. F., Atwood, A. I., and Curran, P. O., "ALE3D Model Predictions and Materials Characterization for the Cookoff Response of PBXN109," in Proceedings of JANNAF 38th Combustion and 20th Propulsion Systems Hazards Subcommittee Meetings, Destin, FL, 2002.

2. McClelland, M. A., Maienschein, J. L., Nichols, A. L., and Yoh, J. J., "Ignition and Initiation Phenomena: Cookoff Violence Prediction”, UCRL-ID-103482-02, 2002.

3. Williams, F. A., Combustion Theory, Addison-Wesley, Redwood City, CA, 1985.

4. McGuire, R. R., and Tarver, C. M., "Chemical Decomposition Models for the Thermal Explosion of Confi ned HMX, TATB, RDX, and TNT Explosives," in Proceedings of 7th International Detonation Symposium, Annapolis, MD, Naval Surface Weapons Center, 1981, pp. 56-64.

5. Belytschko, T., "An Overview of Semidiscretization and Time integration Procedures," in Computational Methods for Transient Analysis, edited by T. Belytschko and T. J. R. Hughes, North-Holland, 1983, pp. 1-65.

6. Wardell, J. F., and Maienschein, J. L., "The Scaled Thermal Explosion Experiment," in Proceedings of 12th International Detonation Symposium, San Diego, CA, Offi ce of Naval Research, 2002.

7. Prior, A. M., "Applications of Implicit and Explicit Finite Element Techniques to Metal Forming", J. of Material Processing Technology, 45, pp. 649-656, 1994. 